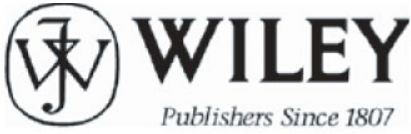

JOHN WILEY \& SONS, LTD, THE ATRIUM, SOUTHERN GATE, CHICHESTER P019 8SQ, UK

\section{***PROOF OF YOUR ARTICLE ATTACHED, PLEASE READ CAREFULLY***}

After receipt of your corrections your article will be published initially within the online version of the journal.

PLEASE AIM TO RETURN YOUR CORRECTIONS WITHIN 48 HOURS OF RECEIPT OF YOUR PROOF, THIS WILL ENSURE THAT THERE ARE NO UNNECESSARY DELAYS IN THE PUBLICATION OF YOUR ARTICLE

- READ PROOFS CAREFULLY

\section{ONCE PUBLISHED ONLINE OR IN PRINT IT IS NOT POSSIBLE TO MAKE ANY FURTHER CORRECTIONS TO YOUR ARTICLE}

- This will be your only chance to correct your proof

- Please note that the volume and page numbers shown on the proofs are for position only

a ANSWER ALL QUERIES ON PROOFS (Queries are attached as the last page of your proof.)

- List all corrections and send back via e-mail to the production contact as detailed in the covering e-mail, or mark all corrections directly on the proofs and send the scanned copy via e-mail. Please do not send corrections by fax or post

\section{- CHECK FIGURES AND TABLES CAREFULLY}

- Check size, numbering, and orientation of figures

- All images in the PDF are downsampled (reduced to lower resolution and file size) to facilitate Internet delivery. These images will appear at higher resolution and sharpness in the printed article

- Review figure legends to ensure that they are complete

- Check all tables. Review layout, title, and footnotes

$\square$ COMPLETE COPYRIGHT TRANSFER AGREEMENT (CTA) if you have not already signed one

- Please send a scanned signed copy with your proofs by e-mail. Your article cannot be published unless we have received the signed CTA

$\square \quad$ OFFPRINTS

- Free access to the final PDF offprint or your article will be available via Author Services only. Please therefore sign up for Author Services if you would like to access your article PDF offprint and enjoy the many other benefits the service offers.

\section{Additional reprint and journal issue purchases}

- Should you wish to purchase additional copies of your article, please click on the link and follow the instructions provided: http://offprint.cosprinters.com/cos/bw/

- Corresponding authors are invited to inform their co-authors of the reprint options available.

- Please note that regardless of the form in which they are acquired, reprints should not be resold, nor further disseminated in electronic form, nor deployed in part or in whole in any marketing, promotional or educational contexts without authorization from Wiley. Permissions requests should be directed to mailto: permissionsuk@wiley.com

- For information about 'Pay-Per-View and Article Select' click on the following link: http://olabout.wiley.com/WileyCDA/Section/id-404512.html 


\title{
Impact of case-relevant and case-irrelevant communication within the surgical team on surgical site infection
}

\author{
F. Tschan $\bullet^{1}$, J.Seelandt ${ }^{1}$, S. Keller ${ }^{1}$, N. K. Semmer ${ }^{2}$, A. Kurmann ${ }^{3}$, D. Candinas ${ }^{3}$ and G. Beldi ${ }^{3}$ \\ ${ }^{1}$ Institute of Work and Organizational Psychology, University of Neuchâtel, Neuchâtel , ${ }^{2}$ Institute of Psychology, University of Berne , and ${ }^{3}$ Department \\ of Visceral Surgery and Medicine, University Hospital and University of Berne, Berne, Switzerland \\ Correspondence to: ProfessorF. Tschan, Institute of Work and Organizational Psychology, University of Neuchâtel, Rue Emile Argand 11, CH 2000 \\ Neuchâtel, Switzerland (e mail: Franziska.Tsehan@unine.ch),
}

Background: Surgical-site infections (SSIs) are the most common complications after surgery. An influence from talking and distractions during surgery on patient outcomes has been suggested, but there is limited evidence. The aim of this prospective observational study was to assess the relationship between intraoperative communication within the surgical team and SSI, and between intraoperative distractions and SSI.

Methods: This prospective observational study included patients undergoing elective, open abdominal procedures. For each procedure, intraoperative case-relevant and case-irrelevant communication, and intraoperative distractions were observed continuously on site. The influence of communication and distractions on SSI after surgery was assessed using logistic regressions, adjusting for risk factors. Results: A total of 167 observed procedures were analysed; their mean duration was $4 \cdot 6(2 \cdot 1) \mathrm{h}$. A total of 24 SSIs (14.4 per cent) were diagnosed. Case-relevant communication during the procedure was independently associated with a reduced incidence of organ/space SSI (propensity score-adjusted odds ratio $0.86,95$ per cent c.i. 0.77 to $0.97 ; P=0.014$ ). Case-irrelevant communication during the closing phase of the procedure was independently associated with increased incidence of incisional SSI (propensity score-adjusted odds ratio $1.29,1.08$ to $1.55 ; P=0.006$ ). Distractions had no association with SSI.

Conclusion: More case-relevant communication was associated with fewer organ/space SSIs, and more case-irrelevant communication during wound closure was associated with incisional SSI.

Paper accepted 31 July 2015

Published online in Wiley Online Library (www.bjs.co.uk). DOI: 10.1002/bjs.9927

\section{Introduction}

Surgical-site infections (SSIs) are the most common complications in surgery, with highest incidence rates after open abdominal procedures ${ }^{1,2}$. Despite attempts to reduce SSIs through evidence-based practices, their incidence remains high ${ }^{3,4}$. Most established risk factors for SSI refer to characteristics of the patient (such as co-morbidities, obesity) and the procedure (such as grade of contamination, duration $)^{5}$. Few studies haye explored the impact of the behaviour of the surgical personnel on $\mathrm{SSI}^{3,6,7}$. These studies focused primarily on compliance with hygiene-related protocols and antiseptic procedures ${ }^{3,6}$, and on the introduction of checklists ${ }^{7}$, but not on effects of teamwork and communication in the operating theatre.

Prospective observational studies during routine surgery emphasize the importance of good teamwork and cooperation. Communication failures can be observed in almost every procedure ${ }^{8}$, and poor teamwork is linked to procedural error ${ }^{9}$. Briefing before surgery and information-sharing during surgery are related to fewer complications and less mortality ${ }^{10}$. With one notable exception ${ }^{10}$, the endpoints of studies investigating teamwork and communication in the operating theatre were not clinical outcomes. There is still little direct evidence of a relationship between intraoperative communication and postoperative complications ${ }^{11}$.

Communication within the surgical team can be case-relevant or case-irrelevant (such as small-talk). Caserelevant communication assures the exchange of information ${ }^{10}$ and supports the team in developing a common understanding of the task ${ }^{12}$. A common understanding, in turn, makes it easier for team members to anticipate developments and to align their actions 
1 accordingly. As a result, team coordination should be

2 smoother ${ }^{13,14}$, and performance should improve. Case-

3 irrelevant communication during surgery is more ambigu-

4 ous; it may promote a positive work environment in the

5 operative theatre ${ }^{15}$, but it also can divert the attention of

6 the surgical team from its main task, and has been found

7 to impair team performance ${ }^{16,17}$.

8 Case-relevant and case-irrelevant communication may

9 have different effects in different phases of an operation.

10 Case-relevant communication is likely to be beneficial

11 throughout the surgery. Case-irrelevant communication is

12 more likely to occur during routine activities, such as the

13 wound closure phase ${ }^{18}$; it may thus distract surgeons while

14 they are suturing, which in turn may increase the risk of

15 incisional infections.

16 In addition to communication, distractions (such as

17 noises, traffic) may also compromise performance ${ }^{17,19}$.

18 Previous studies have found that more distractions and

19 higher noise levels are related to poorer teamwork in the

20 operating theatre ${ }^{17,20}$, and that more lapses in discipline

21 (operationalized as traffic, noise and visitors) are related to

22 a higher incidence of $\mathrm{SSI}^{3}$.

23 The primary goal of this prospective observational study

24 was to test the impact of communication within the surgi-

25 cal team on SSI for major elective open abdominal surgery.
Specifically, the effect of case-relevant and case-irrelevant communication was studied during the whole surgical procedure, as well as during closure of the abdominal wound on deep/organ and incisional SSI. The secondary aim was to test the effect of distractions within the operating theatre on the incidence of SSI.

\section{Methods}

\section{Study design and sample}

Patients undergoing elective open abdominal surgery expected to last for at least $1 \mathrm{~h}$ were included, when observers were available. Exclusion criteria were laparoscopic and emergency procedures, and pre-existing SSI. The operations were performed in the visceral surgery department and included procedures on the upper and lower gastrointestinal tract and the hepatobiliary system. All procedures were open, with median or oblique laparotomy incisions.

The surgical procedures were observed by a team of trained psychologists using a reliable observational system $^{21}$.

Surgical procedures were selected as follows. Each week, the observer team indicated to the study coordinator the days for which observers were available. The coordinator then chose procedures that met the inclusion criteria for those dates. If more than one operation met the inclusion criteria, the first procedure of the day was chosen. For 225 days indicated, 171 suitable procedures were available and observed. Four observed procedures were excluded before analysis; two patients withdrew consent for the follow-up interview, one patient died within 30 days, and one procedure lasted for less than $30 \mathrm{~min}$.

The operations were conducted in a Swiss university hospital. They took place in one of three equally spaced and identical operating theatres, all equipped with a high-efficiency particulate air filter vertical laminar airflow ventilation system. The surgical teams were composed of at least one Board-certified surgeon, at least one resident, one student, one scrub nurse, one or two circulating nurses, at least one anaesthetist and one nurse anaesthetist.

The Internal Review Board of the Hospital approved the study. All patients were informed about data collection. Consent from all staff was obtained.

\section{Patients and procedures}

Preoperative preparation of the patient was performed according to the standards of the clinic and included hair clipping outside the operating theatre, skin disinfection using povidone-iodine-based solution, administration of antibiotics $60-30 \mathrm{~min}$ before the incision, with repetition after $6 \mathrm{~h}$ of surgery. Drain placements including nasogastric tubes; suture technique and postoperative care were performed according to clinical standards.

Characteristics of the patient (age, sex, smoking history within 30 days, excessive alcohol use, body mass index, diabetes, oral steroid use, malignant diagnosis, American Society of Anesthesiologists (ASA) physical status classification) and of the surgical procedure (wound contamination grade, type of surgery, duration of surgery, bowel preparation, blood transfusion during surgery, and whether or not a drain was placed) were extracted from the patient file, surgery report and anaesthetics report. It was also calculated whether the duration of the surgery was above standard values (the 75 th percentile) for each type of surgery, as part of the National Nosocomial Infections Surveillance (NNIS) Risk Index, which estimates risks of infection after different procedures ${ }^{2}$.

\section{Primary study endpoint}

Independent and trained infection control practitioners assessed the presence of SSI according to standards defined by the Centers for Disease Control and Prevention ${ }^{22}$. This protocol also includes a follow-up phone call 30 days after surgery. If an SSI was suspected, consultants or general 
1 practitioners were asked to confirm and classify it. SSIs

2 were grouped as: superficial incisional, deep incisional, or

3 organ/space SSI. In line with other authors ${ }^{3,23}$, superficial

4 and deep incisional SSI were combined into one category.

5

\section{Assessment of communication and distractions}

8 Case-relevant and case-irrelevant communication, as well

9 as distractions during the procedure, were assessed by

10 direct observation. Trained psychologists observed the

11 operations using an event-coding observational system that

12 has been shown to be reliable ${ }^{21}$. Observers were located in

13 the operating theatre, about $1.5 \mathrm{~m}$ from the operation table,

14 facing the lead surgeon. The observations started when the

15 patient was wheeled into the theatre, and ended with the

16 last suture. Analyses refer to the time between incision and

17 insertion of the last stitch.

18 Each exchange of communication within the sterile team

19 (surgeons and scrub nurses), and between the sterile team

20 and anaesthetists, was time-stamped and coded as either

21 case-relevant or case-irrelevant. An exchange of commu-

22 nication was defined as one or several verbal statements

23 related to the same theme and not interrupted by pauses ${ }^{21}$.

24 Case-relevant communication was defined as: exchange

25 about the patient in surgery or the procedure performed.

26 This included: communication about current or future

27 actions and explanations (for example, the surgeons talk

28 about the next steps of the procedure); leadership state-

29 ments (for example, the surgeon requests insertion of a

30 nasogastric tube); and case-related teaching (for example,

31 the surgeon replies to a question on the use of a specific instrument $)^{21}$. Case-relevant communication was expressed as the mean per hour for the entire procedure.

Case-irrelevant communication was coded when members of the sterile team: talked about topics unrelated to the patient or the procedure; or joked or laughed ${ }^{21}$. Case-irrelevant communication was also expressed as the mean per hour for the entire procedure, and as the mean count during the wound closure phase. The closure phase was defined as the last $20 \mathrm{~min}$ of the procedure, because this is the duration required for suturing the abdominal fascia and skin after midline or oblique laparotomy. This was independent of the duration of the whole procedure.

Distraction coding included the following events: noise events produced by a member of the non-sterile team (for instance loud noises when opening packages); traffic in the operating theatre (operationalized by counting doors to the theatre that were opened); and side-conversations in the theatre (non-sterile personnel, including the anaesthetist, scrub nurses, technicians and visitors engaging in conversation with one another, unless those conversations were very quiet). Noise events, door openings

and side-conversations were each expressed as the mean per hour.

To assess interobserver agreement, 29 (17.4 per cent) of the 167 operations were observed simultaneously by two observers. Cohen's weighted $\kappa$ was used to assess interobserver agreement, based on 5-min intervals. All values of $\kappa$ were greater than $0 \cdot 70$, which is considered substantial agreement ${ }^{24}$.

\section{Statistical analysis}

The prespecified primary outcomes were incisional or organ/space SSI. Descriptive information was expressed as frequencies and percentages for categorical variables, and as mean(s.d.) for continuous variables. To assess associations of SSI rates with patient characteristics, procedure characteristics, communication and distractions, univariable logistic regression analyses were performed. Because the number of outcome events (SSIs) was small, conventional multivariable analysis with all baseline characteristics as co-variables was not feasible. Therefore the propensity score co-yariable adjustment technique was used ${ }^{25,26}$. The variables included in the propensity score were selected based on a priori considerations (Table 1).

Probability values and 95 per cent c.i. were two-tailed. SPSS ${ }^{\circledR}$ for Windows ${ }^{\circledR}$ version 22 software (IBM, Armonk, New York, USA) was used for analysis; $P<0.050$ was considered statistically significant. Because no previous research provided expected effect sizes for the type of procedures, sample size considerations were based on the recommendations of Peduzzi and colleagues ${ }^{27}$, assuming an overall infection rate of 15-20 per cent.

\section{Results}

A total of 167 observed procedures were analysed; their mean duration was $4 \cdot 6(2 \cdot 1) \mathrm{h}$. Twenty-four patients (14.4 per cent) developed an SSI; 14 (8.4 per cent) were deep/organ space SSI and ten (6.0 per cent) incisional SSI. Descriptive statistics and results of univariable logistic regression relating patient characteristics and surgery characteristics to SSI are shown in Table 1. No patient characteristic or procedure type was significantly related to SSI. Among the surgical risk factors, blood transfusion during surgery was a significant univariable risk for incisional, as well for organ/space SSI.

\section{Case-relevant and case-irrelevant communication}

Separate univariable analyses showed that case-relevant communication throughout the procedure was significantly associated with a lower risk of space/organ SSI. 
1 Table 1 Patient and surgery characteristics; descriptive statistics and univariable relationships to incisional and organ/space surgical-site 2 infection

3

4

6

7

8

9

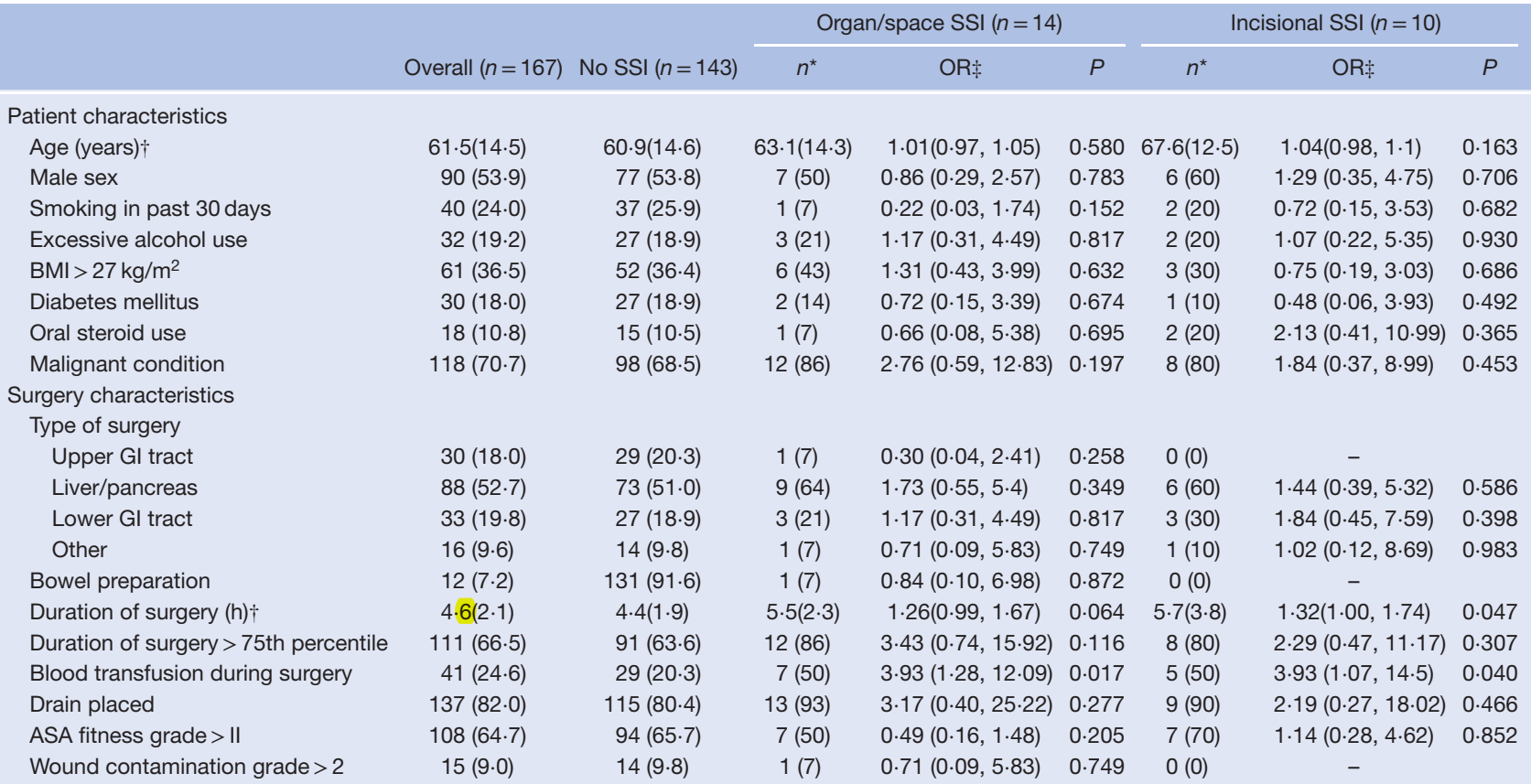

*Number of patients with percentages in parentheses unless indicated otherwise; values are $\uparrow$ mean(s.d.) and $\$ 95$ per cent c.i. in parentheses. All patient and surgery characteristics were included in the propensity score. SSI, surgical-site infection; OR, odds ratio; BMI, body mass index; GI, gastrointestinal; ASA, American Society of Anesthesiologists.

Table 2 Communication and distractions during surgery; descriptiye statistics, univariable and propensity score-adjusted relationship to incisional or organ/space surgical-site infection

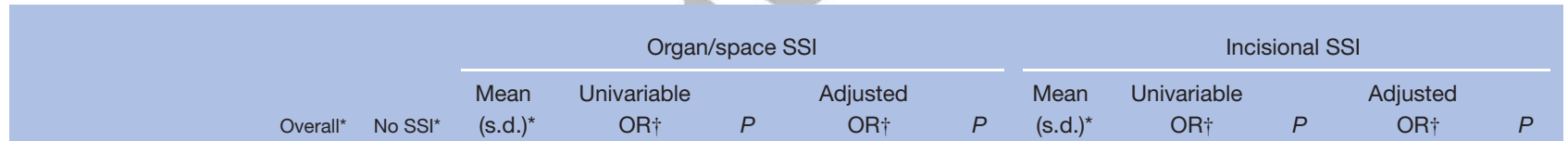

\begin{tabular}{|c|c|c|c|c|c|c|c|c|c|c|c|c|}
\hline \multicolumn{13}{|l|}{ Communication } \\
\hline $\begin{array}{l}\text { Case-relevant } \\
\text { communication }\end{array}$ & $19 \cdot 2(6 \cdot 5)$ & $19 \cdot 4(6 \cdot 7)$ & $15 \cdot 4(3 \cdot 2)$ & $0.90(0.81,0.99)$ & 0.030 & $0.86(0.77,0.97)$ & 0.014 & $21 \cdot 6(4 \cdot 9)$ & $1.05(0.96,1.16)$ & 0.296 & $1.08(0.95,1.23)$ & 0.239 \\
\hline \multicolumn{13}{|l|}{$\begin{array}{l}\text { Case-irrelevant } \\
\text { communication }\end{array}$} \\
\hline Whole procedure & $6 \cdot 2(4 \cdot 3)$ & $6 \cdot 0(3 \cdot 7)$ & $5 \cdot 9(6 \cdot 1)$ & $0.98(0.85,1.13)$ & 0.780 & $1.00(0.86,1.17)$ & 0.955 & $9 \cdot 5(7 \cdot 8)$ & $1.13(1.02,1 \cdot 26)$ & 0.023 & $1.19(1.04,1.36)$ & 0.012 \\
\hline During closure & $3 \cdot 1(3 \cdot 2)$ & $2 \cdot 9(2 \cdot 9)$ & $2.92(3.3)$ & $1.01(0.83,1.22)$ & 0.939 & $0.98(0.81,1.2)$ & 0.869 & $6 \cdot 9(4 \cdot 5)$ & $1.31(1.12-1.53)$ & 0.001 & $1.29(1.08,1.55)$ & 0.006 \\
\hline \multicolumn{13}{|l|}{ Distractions } \\
\hline Noise & $10 \cdot 2(4 \cdot 4)$ & $10 \cdot 4(4 \cdot 4)$ & $8 \cdot 3(3 \cdot 3)$ & $0.87(0.75,1.02)$ & 0.088 & $0.84(0.71,1.01)$ & 0.057 & $10 \cdot 3(4 \cdot 7)$ & $1.00(0.86,1.16)$ & 0.993 & $0.97(0.82,1.15)$ & 0.723 \\
\hline Door openings (traffic) & $31 \cdot 8(6 \cdot 3)$ & $31 \cdot 8(6 \cdot 6)$ & $31 \cdot 8(4 \cdot 6)$ & $1.00(0.92,1.09)$ & 0.990 & $0.99(0.90,1.09)$ & 0.787 & $31 \cdot 2(5 \cdot 7)$ & $0.98(0.89,1.09)$ & 0.749 & $0.93(0.83,1.05)$ & 0.245 \\
\hline Side-conversations & $10 \cdot 5(5 \cdot 2)$ & $10 \cdot 5(5 \cdot 4)$ & $9 \cdot 9(3 \cdot 3)$ & $0.98(0.87,1.09)$ & 0.684 & $0.98(0.87,1.10)$ & 0.674 & $12 \cdot 6(4 \cdot 9)$ & $1.07(0.96,1.19)$ & 0.222 & $1.08(0.95,1.23)$ & 0.229 \\
\hline
\end{tabular}

*Values are mean(s.d.) events per hour. fvalues in parentheses are 95 per cent c.i. SSI, surgical-site infection; OR, odds ratio.

Case-irrelevant communication during the whole procedure, and during the closure phase, was a significant univariable risk factor for incisional SSI (Table 2).

Taking known risk factors for SSI into account, adjusted logistic regression analysis was performed, including the propensity score (Table 2). As information on ASA fitness grade, which is part of the NNIS Risk Index, was missing for three procedures (no SSI), the adjusted logistic regression analysis is based on 164 operations.

The adjusted model shows that more case-relevant communication during the whole procedure (events per hour) was associated with a decreased incidence in organ/space SSI (Fig. 1) (adjusted odds ratio (OR) 0.86, 95 per cent c.i. 0.77 to $0.97 ; P=0.014$ ). 
1

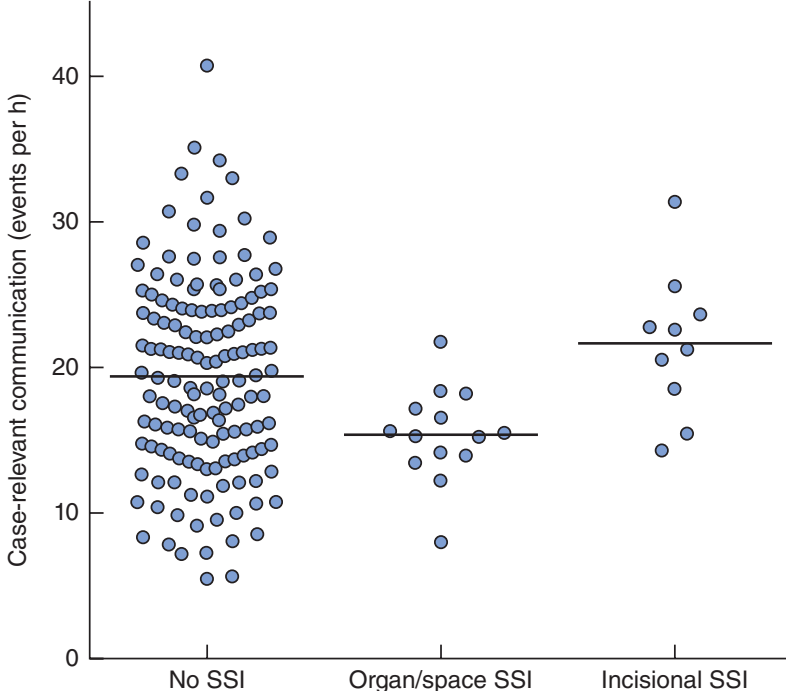

Fig. 1 Case-relevant communication per hour for procedures with no surgical-site infection (SSI) (143 patients), organ/space SSI (14) or incisional SSI (10). Bars denote mean values

Regarding incisional SSI, the adjusted model for case-irrelevant communication throughout the procedure (events per hour) showed that more case-irrelevant communication overall was related to a higher incidence of incisional SSI (adjusted OR 1.19, 1.04 to $1.36 ; P=0.012$ ). In particular, more case-irrelevant communication during closure was related to a higher incidence of incisional SSI (adjusted OR 1.29, 1.08 to $1.55 ; P=0.006$ ). To investigate whether the effect was due to case-irrelevant communication overall, or to case-irrelevant communication during the closure phase, a logistic regression model was used, adjusting for the effect of case-irrelevant communication during closure for the propensity score, as well as for case-irrelevant communication before closure. The results show that more case-irrelevant communication during closure remained significantly related to a higher risk of incisional SSI (adjusted OR 1.23,1.01 to $1.50 ; P=0.048$ ), whereas case-irrelevant communication before closure was not significant (adjusted OR $1.09,0.92$ to $1.29 ; P=0.308$ ) (Fig. 2).

\section{Perioperative distractions}

None of the observed distractions (noise events, door openings, side-conversations) was significantly related to incisional or organ/space SSI in univariable or propensity score-adjusted logistic regression analyses (Table 2).

\section{Discussion}

In this study, more case-relevant communication during the whole procedure was associated with a lower risk of

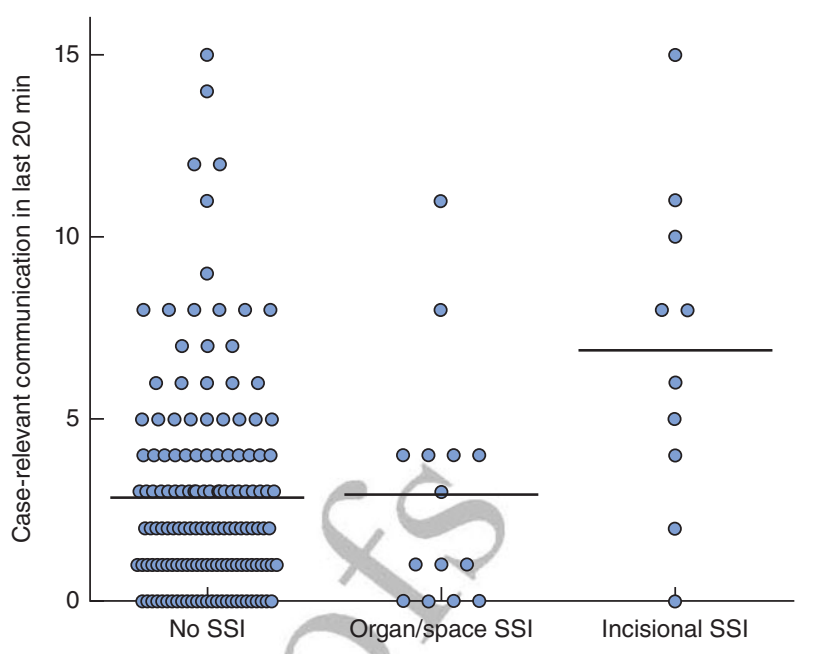

Fig. 2 Case-irrelevant communication in the last $20 \mathrm{~min}$ of procedures with no surgical-site infection (SSI) (143 patients), organ/space SSI (14) or incisional SSI (10). Bars denote mean values

organ/space SSI, whereas more case-irrelevant communication during the closure phase was associated with an increased risk of incisional SSI. Distractions were not associated with SSI.

Case-relevant communication assures the exchange of information ${ }^{28,29}$; less sharing of information has been found to be related to more complications ${ }^{10}$. Exchanging case-relevant information may foster a shared understanding of the task within the team. Indeed, studies from medicine and other fields have shown that task-related communication helps team members to cooperate more smoothly ${ }^{30}$; this is likely to be particularly important during difficult phases of the operation ${ }^{10}$. Smooth cooperation implies that the surgeons do not have to switch attention between their primary task and the need to assure team coordination, thus avoiding microinterruptions. In addition, persistent misunderstandings and loss of information have been observed frequently in surgery ${ }^{8,31}$; they may be attenuated by exchanging more case-relevant communication during the procedure.

Things are more complex for case-irrelevant communication. Case-irrelevant communication may improve team climate. Relaxed communication and the use of humour are seen as an important part of team-building processes $^{9,32}$. However, case-irrelevant communication may also divert attention from the primary task and may impair performance ${ }^{17,19}$. The present results support the distracting effect of case-irrelevant communication under specific circumstances: case-irrelevant communication predicted incisional SSI. It appears that case-irrelevant 
1 communication during closure was responsible for the 2 higher rate of wound infection.

3 During closure, the most difficult part of the operation 4 is over, and routine activities are left for most team mem5 bers (clearing and removing equipment). During routine 6 phases, teams are more likely to engage in case-irrelevant 7 talk $^{18}$, which may increase the probability of minor errors 8 for several reasons. First, performing a manual task while

engaging in an unrelated conversation is a form of multitasking, which may increase the likelihood of errors ${ }^{33}$. Second, negative effects of demanding tasks often manifest themselves only after the period of high workload ${ }^{34}$, because attentiveness often decreases when people start to relax. For example, residents working long hours have more car accidents on their way home ${ }^{35}$. Third, although supervised by an experienced surgeon, closure of the abdominal wall is often performed by a junior surgeon, for whom suturing is not yet a routine task $\mathrm{k}^{36,37}$. In contrast to experienced surgeons, who can shield themselves quite well from distractions ${ }^{38,39}$, the performance of junior surgeons, including manual performance, tends to degrade in distracting environments ${ }^{16,40-42}$. Lower concentration may induce less careful suturing, more damaged tissue, or too much tension in the sutures, thus raising the risk of incisional SSI. Fatigue may be an additional aggravating factor $^{43}$.

These results confirm the findings of a previous study ${ }^{3}$ suggesting that lapses in discipline increase the risk of SSI. They refine these earlier findings by identifying the most sensitive phase (wound closure) for this effect. It is, however, not clear why only case-irrelevant communication affected the surgeons in the closure phase, and other distractions did not. It is possible that conversation conveys meaning to a greater extent than other distractions. Meaningful noise is difficult to ignore ${ }^{44}$, and is more likely to impair concentration and coordination ${ }^{17}$

This study also adds to the growing evidence that the quality of teamwork in the operating theatre is related to patient outcomes ${ }^{11}$. A shared understanding of important characteristics of a situation is a central feature of good teamwork, as suggested by the finding that operations done by familiar teams result in fewer complications ${ }^{45,46}$. Case-related communication may be an efficient way to achieve this common understanding. However, there is an alternative explanation that cannot be ruled out: it is possible that case-related is simply a marker of good teamwork. This alternative explanation would imply that improving teamwork would result in better communication; the present interpretation implies that improving communication would result in better teamwork.
Using behaviour observation as a method, and simultaneously assessing case-relevant and case-irrelevant communication as well as distractions, constitutes a strength of this study. This method allowed communication to be assessed separately during the closure phase of the procedure. Furthermore, whereas most other studies investigated procedures lasting less than $2 \mathrm{~h}^{47}$, this study focused on long, open abdominal procedures with the highest risk of SSI. A strength of this study is also the focus on everyday behaviour, rather than on communication failure ${ }^{48,49}$; general, ordinary aspects of communication measurably affected SSI. This supports previous findings that intraoperative behaviour that is not dramatic, yet lacks focus, may cause minor errors that often go unnoticed ${ }^{3}$.

The present study is limited by the fact that a controlled randomized design was not feasible; instead a prospective design was adopted. However, reverse causation is not a plausible explanation for the present results, because SSIs were assessed after the operation and pre-existing SSIs were excluded. Most importantly, the exact mechanisms linking communication events to SSI remain unexplored. Because this was a single-site study and only elective open abdominal surgery was included, generalization of the results is limited. Many confounding factors, including team climate, and thus probably also communication, may vary considerably between hospitals ${ }^{50}$.

This study measured the effect of intraoperative communication on SSIs because they are the most frequent complications in surgery. The results highlight the importance of understanding intraoperative communication. Case-relevant communication during the whole procedure appeared to reduce the risk of organ/space SSI, whereas case-irrelevant communication during the closure phase seemed to increase the risk of incisional SSI. Yet, case-irrelevant communication can foster a positive team climate $^{9}$, and it is understandable that the surgical team relaxes after a long and difficult procedure ${ }^{18}$. Prohibiting case-irrelevant communication might create tension and frustration, which may have detrimental effects. It may be more appropriate for teams to adapt behaviour to the situation by allowing a short period of tension release or a break, before focusing anew on the task of wound closure $^{51}$.

\section{Acknowledgements}

The authors thank B. Dubach (head nurse) and U. Klopsch (technician) for their support; P. Jüni for statistical advice and critical comments on the manuscript; K. Tal for editorial assistance; C. Gfeller, S. Huber, N. Jenni, F. Leupi, M. Monnier and A. Püschel (observers) for assisting in data 
1 collection; and D. Brand, M. Künzi and B. Uhlmann (study 2 nurses) for collecting the follow-up data.

3 Disclosure: The authors declare no conflict of interest. 4

\section{References}

1 Sax H, Uçkay I, Balmelli C, Bernasconi E, Boubaker K, Mühlemann K et al. Overall burden of healthcare-associated infections among surgical patients: results of a national study. Ann Surg 2011; 253: 365-370.

2 National Nosocomial Infections Surveillance System. National Nosocomial Infections Surveillance (NNIS) system report, data summary from January 1992 through June 2004, issued October 2004. Am F Infect Control 2004; 32: 470-485.

3 Beldi G, Bisch-Knaden S, Banz V, Mühlemann K, Candinas D. Impact of intraoperative behavior on surgical site infections. Am 7 Surg 2009; 198: 157-162.

$4 \mathrm{Mu} \mathrm{Y,} \mathrm{Edwards} \mathrm{JR,} \mathrm{Horan} \mathrm{TC,} \mathrm{Berrios-Torres} \mathrm{SI,} \mathrm{Fridkin}$ SK. Improving risk-adjusted measures of surgical site infection for the National Healthcare Safety Network. Infection Control Hosp Epidemiol 2011; 32: 970-986.

5 Mangram AJ, Horan TC, Pearson ML, Silver LC, Jarvis WR. Guideline for prevention of surgical site infection, 1999. Centers for Disease Control and Prevention (CDC) hospital infection control practices advisory committee. Am J Infect Control 1999; 27: 97-132.

6 Pittet D, Allegranzi B, Sax H, Dharan S, Pessoa-Silva CL, Donaldson L et al. Evidence-based model for hand transmission during patient care and the role of improved practices. Lancet Infect Dis 2006; 6: 641-652.

7 Haynes AB, Weiser TG, Berry WR, Lipsitz SR, Breizat AH, Dellinger EP et al. A surgical safety checklist to reduce morbidity and mortality in a global population. NEngl $f$ Med 2009; 360: 491-499.

8 Lingard L, Espin S, Whyte S, Regehr G, Baker GR, Reznick R etal. Communication failures in the operating room: an observational classification of recurrent types and effects. Qual Saf Health Care 2004; 13: 330-334.

9 Catchpole K, Mishra A, Handa A, McCulloch P. Teamwork and error in the operating room: analysis of skills and roles. Ann Surg 2008; 247: 699-706.

10 Mazzocco K, Petitti DB, Fong KT, Bonacum D, Brookey J, Graham S et al. Surgical team behaviors and patient outcomes. Am 7 Surg 2009; 197: 678-685.

11 Nagpal K, Vats A, Lamb B, Ashrafian H, Sevdalis N, Vincent $\mathrm{C}$ et al. Information transfer and communication in surgery: a systematic review. Ann Surg 2010; 252: 225-239.

12 Westli HK, Johnsen BH, Eid J, Rasten I, Brattebo G. Teamwork skills, shared mental models, and performance in simulated trauma teams: an independent group design. Scand 7 Trauma Resusc Emerg Med 2010; 18: 47.

13 Weaver SJ, Rosen MA, DiazGranados D, Lazzara EH, Lyons R, Salas E et al. Does teamwork improve performance in the operating room? A multilevel evaluation. ft Comm $\mathcal{F}$ Qual Patient Saf 2010; 36: 133-142.
14 Hazlehurst B, McMullen CK, Gorman PN. Distributed cognition in the heart room: how situation awareness arises from coordinated communications during cardiac surgery. 7 Biomed Inform 2007; 40: 539-551.

15 Nurok M, Evans LA, Lipsitz S, Satwicz P, Kelly A, Frankel A. The relationship of the emotional climate of work and threat to patient outcome in a high-volume thoracic surgery operating room team. BMF Qual Saf 2011; 20: $237-242$.

16 Feuerbacher RL, Funk K, Spight DH, Diggs BS, Hunter JG. Realistic distractions and interruptions that impair simulated surgical performance by novice surgeons. Arch Surg 2012; 147: 1026-1030.

17 Wheelock A, Suliman A, Wharton R, Babu ED, Hull L, Vincent $\mathrm{C}$ et al. The impact of operating room distractions on stress, workload, and teamwork. Ann Surg 2015; 261 : 1079-1084.

18 Katz P. Ritual in the operating-room. Ethnology 1981; 20: $335-350$.

19 Sevdalis N, Healey AN, Vincent CA. Distracting communications in the operating theatre. 7 Eval Clin Pract 2007; 13: 390-394.

20 Kurmann A, Peter M, Tschan F, Mühlemann K, Candinas D, Beldi G. Adverse effect of noise in the operating theatre on surgical-site infection. Br F Surg 2011; 7: 1021-1025.

21 Seelandt JC, Tschan F, Keller S, Beldi G, Jenni N, Kurmann A et al. Assessing distractors and teamwork during surgery: developing an event-based method for direct observation. BM7 Qual Saf 2014; 23: 918-929.

22 Emori TG, Culver DH, Horan TC, Jarvis WR, White JW, Olson DR et al. National Nosocomial Infections Surveillance System (NNIS): description of surveillance methods. Am F Infect Control 1991; 19: 19-35.

23 Blumetti J, Luu M, Sarosi G, Hartless K, McFarlin J, Parker $\mathrm{B}$ et al. Surgical site infections after colorectal surgery: do risk factors vary depending on the type of infection considered? Surgery 2007; 142: 704-711.

24 Landis JR, Koch GG. The measurement of observer agreement for categorical data. Biometrics 1977; 33 : $159-174$.

25 da Costa BR, Gahl B, Jüni P. Tools and techniques - statistics: propensity score techniques. EuroIntervention 2014; 10: 761-767.

26 Austin PC. An introduction to propensity score methods for reducing the effects of confounding in observational studies. Multivariate Behav Res 2011; 46: 399-424.

27 Peduzzi P, Concato J, Kemper E, Holford TR, Feinstein AR. A simulation study of the number of events per variable in logistic regression analysis. 7 Clin Epidemiol 1996; 49: 1373-1379.

28 Healey AN, Undre S, Vincent CA. Defining the technical skills of teamwork in surgery. Qual Saf Health Care 2006; 15: 231-234.

29 Wong HW, Forrest D, Healey A, Shirafkan H, Hanna GB, Vincent CA et al. Information needs in operating room 
41 Hsu KE, Man FY, Gizicki RA, Feldman LS, Fried GM. Experienced surgeons can do more than one thing at a time: effect of distraction on performance of a simple laparoscopic and cognitive task by experienced and novice surgeons. Surg Endosc 2008; 22: 196-201.

42 Gallagher AG, Satava RM, O'Sullivan GC. Attentional capacity: an essential aspect of surgeon performance. Ann Surg 2015; 261: e60-e61.

43 Denisco R, Drummond J, Gravenstein J. The effect of fatigue on the performance of a simulated anesthetic monitoring task. 7 Clin Monitor Comp 1987; 3: 22-24.

44 Engelmann CR, Neis JP, Kirschbaum C, Grote G, Ure BM. A noise-reduction program in a pediatric operation theatre is associated with surgeon's benefits and a reduced rate of complications: a prospective controlled clinical trial. Ann Surg 2014; 259:1025-1033.

45 Brown ML, Parker SE, Quiñonez LG, Li Z, Sundt TM. Can the impact of change of surgical teams in cardiovascular surgery be measured by operative mortality or morbidity? A propensity adjusted cohort comparison. Ann Surg 2011; 253: 385-392.

46 Kurmann A, Keller S, Tschan-Semmer F, Seelandt J, Semmer N, Candinas D et al. Impact of team familiarity in the operating room on surgical complications. World 7 Surg 2014; 38: 3047-3052.

47 Healey AN, Sevdalis N, Vincent C. Measuring intra-operative interference from distraction and interruption observed in the operating theatre. Ergonomics 2006; 49: 589-604.

48 Gawande AA, Zinner MJ, Studdert DM, Brennan TA. Analysis of errors reported by surgeons at three teaching hospitals. Surgery 2003; 133: 614-621.

49 Greenberg CC, Regenbogen SE, Studdert DM, Lipsitz SR, Rogers SO, Zinner MJ et al. Patterns of communication breakdowns resulting in injury to surgical patients. $7 \mathrm{Am}$ Coll Surg 2007; 204: 533-540.

50 Sexton JB, Makary MA, Tersigni AR, Pryor D, Hendrich A, Thomas EJ et al. Teamwork in the operating room: frontline perspectives among hospitals and operating room personnel. Anesthesiology 2006; 105: 877-884.

51 Engelmann C, Schneider M, Kirschbaum C, Grote G, Dingemann J, Schoof $\mathrm{S}$ et al. Effects of intraoperative breaks on mental and somatic operator fatigue: a randomized clinical trial. Surg Endosc 2011; 25: $1245-1250$. 


\section{QUERIES TO BE ANSWERED BY AUTHOR}

IMPORTANT NOTE: Please mark your corrections and answers to these queries directly onto the proof at the relevant place. DO NOT mark your corrections on this query sheet.

Queries from the Copyeditor:

AQ1. Please confirm that given names (red) and surnames/family names (green) have been identified correctly 


\section{WILEY AUTHOR DISCOUNT CLUB}

We would like to show our appreciation to you, a highly valued contributor to Wiley's publications, by offering a unique $\mathbf{2 5 \%}$ discount off the published price of any of our books*.

All you need to do is apply for the Wiley Author Discount Card by completing the attached form and returning it to us at the following address:

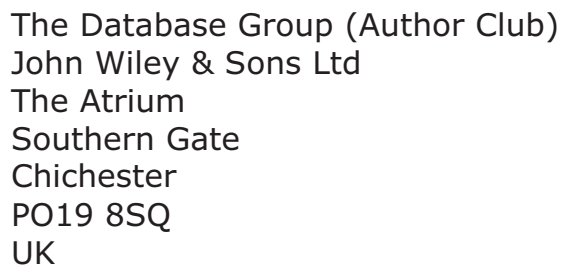

After registering you will receive your Wiley Author Discount Card with a special promotion code, which you will need to quote whenever you order books direct from us.

The quickest way to order your books from us is via our European website at:

\section{http: / / www.wileyeurope.com}

Key benefits to using the site and ordering online include:

Real-time SECURE on-line ordering

Easy catalogue browsing

Dedicated Author resource centre

Opportunity to sign up for subject-orientated e-mail alerts

Alternatively, you can order direct through Customer Services at:

cs-books@wiley.co.uk, or call +44 (0)1243 843294, fax +44 (0)1243843303

So take advantage of this great offer and return your completed form today.

Yours sincerely,<smiles>CCCCOC(=O)CCCC</smiles>

Verity Leaver Group Marketing Manager author@wiley.co.uk 


\section{REGISTRATION FORM For Wiley Author Club Discount Card}

To enjoy your $25 \%$ discount, tell us your areas of interest and you will receive relevant catalogues or leaflets from which to select your books. Please indicate your specific subject areas below.

\begin{tabular}{|c|}
\hline $\begin{array}{l}\text { Accounting } \\
\text { Public } \\
\text { Corporate }\end{array}$ \\
\hline $\begin{array}{l}\text { Chemistry } \\
\text { Analytical } \\
\text { Industrial/Safety } \\
\text { Organic } \\
\text { Inorganic } \\
\text { Polymer } \\
\text { Spectroscopy }\end{array}$ \\
\hline $\begin{array}{l}\text { Encyclopedia/Reference } \\
\text { Business/Finance } \\
\text { Life Sciences } \\
\text { Medical Sciences } \\
\text { Physical Sciences } \\
\text { Technology }\end{array}$ \\
\hline
\end{tabular}

Earth \& Environmental Science

Hospitality

\section{Genetics}

Bioinformatics/

Computational Biology

Proteomics

Genomics

Gene Mapping

Clinical Genetics
[ ]

[]

[ ]

[]

[ ]

Medical Science

Cardiovascular

Diabetes

Endocrinology

Imaging

Obstetrics/Gynaecology

Oncology

Pharmacology

Psychiatry

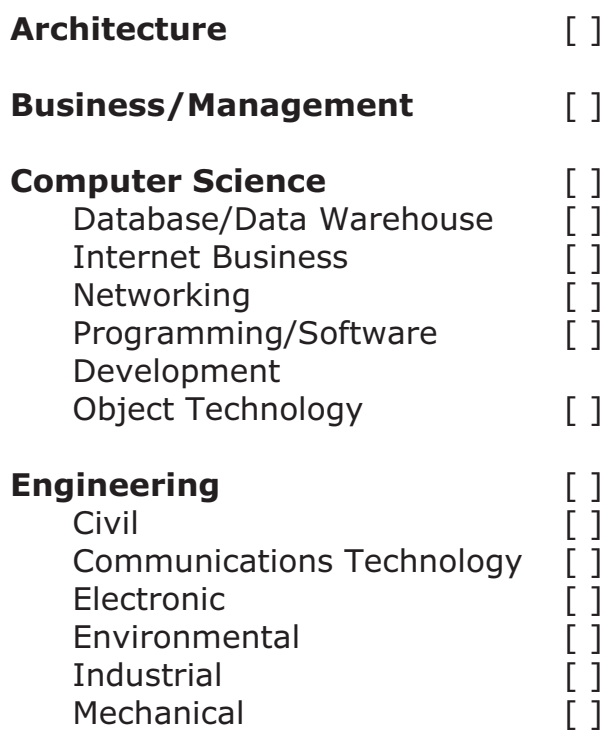

Finance/Investing [ ]

Economics []

Institutional []

Personal Finance [ ]

Life Science [ ]

Landscape Architecture [ ]

Mathematics [ ]

Statistics

\section{Manufacturing}

Materials Science

Psychology
Clinical
Forensic
Social \& Personality
Health \& Sport
Cognitive
Organizational
Developmental \& Special Ed
Child Welfare
Self-Help

[]
[]
[]
[]
[]
[]
[]
[]
[]
[]
[]

Physics/Physical Science [ ] 
I confirm that I am (*delete where not applicable):

a Wiley Book Author/Editor/Contributor* of the following book(s):

ISBN:

ISBN:

a Wiley Journal Editor/Contributor/Editorial Board Member* of the following journal(s):

Date:

\section{PLEASE COMPLETE THE FOLLOWING DETAILS IN BLOCK CAPITALS:}

TITLE: (e.g. Mr, Mrs, Dr)

FULL NAME:

JOB TITLE (or Occupation):

DEPARTMENT:

COMPANY/INSTITUTION:

ADDRESS:

TOWN/CITY:

COUNTY/STATE:

COUNTRY:

POSTCODE/ZIP CODE:

DAYTIME TEL:

FAX:

E-MAIL:

\section{YOUR PERSONAL DATA}

We, John Wiley \& Sons Ltd, will use the information you have provided to fulfil your request. In addition, we would like to:

1. Use your information to keep you informed by post of titles and offers of interest to you and available from us or other Wiley Group companies worldwide, and may supply your details to members of the Wiley Group for this purpose.

[ ] Please tick the box if you do NOT wish to receive this information

2. Share your information with other carefully selected companies so that they may contact you by post with details of titles and offers that may be of interest to you.

[ ] Please tick the box if you do NOT wish to receive this information.

\section{E-MAIL ALERTING SERVICE}

We also offer an alerting service to our author base via e-mail, with regular special offers and competitions. If you DO wish to receive these, please opt in by ticking the box [ ].

If, at any time, you wish to stop receiving information, please contact the Database Group (databasegroup@wiley.co.uk) at John Wiley \& Sons Ltd, The Atrium, Southern Gate, Chichester, PO19 8SQ, UK.

This offer is exclusive to Wiley Authors, Editors, Contributors and Editorial Board Members in acquiring books for their personal use. There should be no resale through any channel. The offer is subject to stock availability and may not be applied retrospectively. This entitlement cannot be used in conjunction with any other special offer. Wiley reserves the right to vary the terms of the offer at any time.

PLEASE RETURN THIS FORM TO:

Database Group (Author Club), John Wiley \& Sons Ltd, The Atrium, Southern Gate, Chichester, PO19 8SQ, UK author@wiley.co.uk Fax: $+44(0) 1243770154$ 